This item is the archived peer-reviewed author-version of:

Body size, developmental instability, and climate change

\title{
Reference:
}

Pape Møller Andreas, Erritzøe Johannes, Van Dongen Stefan.- Body size, developmental instability, and climate change Evolution - ISSN 0014-3820 - 72:10(2018), p. 2049-2056

Full text (Publisher's DOI): https://doi.org/10.1111/EVO.13570

To cite this reference: https://hdl.handle.net/10067/1529650151162165141 


\section{Body size, developmental instability and climate change}

Anders Pape Møller ${ }^{1}$, Johannes Erritzøe ${ }^{2}$ and Stefan van Dongen ${ }^{3}$

${ }^{1}$ Ecologie Systématique Evolution, Université Paris-Sud, CNRS, AgroParisTech, Université Paris-Saclay, F-91405 Orsay Cedex, France

${ }^{2}$ Taps Old Rectory, DK-6040 Christiansfeld, Denmark

${ }^{3}$ Department of Biology, Campus Drie Eiken, Building D. D. 137,

Word count: 5608 stefan.vandongen@uantwerpen.be 
A. P. Møller et al.: Body size, developmental instability and climate

23

24 
25 Development is often temperature-dependent. We hypothesized smaller size and

26 larger asymmetry with increasing temperatures. However, we also predicted associations with asymmetry to differ among traits that differ in their degree of functional importance (especially the functional wings in migratory birds were predicted to be more canalized), timing of development (skeletal (femur, tarsus and humerus) vs feather (wing and tail traits), although it is difficult to make strong predictions a priori. We analyzed a large dataset of which we included to species with at least 20 specimens resulting in 5533 asymmetry values in 1593 individuals from 66 species. There was a consistent significant decrease in size with temperature across all traits. Fluctuating asymmetry for wings and femur was on average lower, suggesting higher canalization, and it decreased with migration distance, while that was not the case for the other traits. Fluctuating interaction between temperature, migration distance and character, the to predict the effects of environmental changes on the developmental instability asymmetry-temperature response was similar in migratory and resident species. These findings imply that climate warming reduces size of all traits and decreases developmental instability of wings in birds. Further research will be required to study the specific role of more intense selection and/ or canalization of different traits. 
48 KEY WORDS: Birds, body size, climate change, development, fluctuating

49 asymmetry, migration distance.

50

51 


\section{Introduction}

Carl Bergmann (1847) documented that temperature drives spatial patterns of body size. This general phenomenon of increasing size with latitude was subsequently termed Bergmann's rule. However, an extensive scientific literature dealing with spatial and temporal patterns of phenotypic variation has reported many exceptions to this rule (e. g. Olson et al. 2009; Teplitsky and Millien 2014).

The metabolic underpinnings of Bergmann's rule are that larger individuals conserve body heat more efficiently than small conspecifics (Bergmann 1847). It is important to emphasize that this is only one of several explanations for this pattern since Bergmann's rule also applies to many poikilotherms. Furthermore, larger individuals may suffer from hyperthermia because of low heat loss efficiency. If we consider spatial patterns of variation in size as stated by Bergmann's rule, such geographical differences in body size may come about for different reasons. For example, James (1970) suggested that different phenotypes may have evolved in different climates, or that spatial variation in selection results in spatial clines in size as described by Bergmann. Therefore, the potential causes of temporal body size shifts include effects of temperature on development, fecundity and mortality because climate variability increases with climate change.

Recently, Bergmann's rule and other patterns of spatial and temporal variation in size have attracted increasing attention because climate change may 
74 have predictable outcomes. Indeed, there is an extensive literature providing a

75 link between temporal change in body size and climate change (reviews in

76 Yom-Tov and Geffen 2011; Gardner et al. 2011; Van Buskirk et al. 2010).

77 These morphological changes can have important evolutionary consequences.

78 For example, Van Gils et al. (2016) showed for the long distance migratory knot

79 Calidris canutus that recent body shrinkage of birds in the Arctic has resulted in

80 a deterioration in survival prospects. This pattern of change in body size was

81 until recently so pronounced that it was considered a general consequence of

82 climate warming (reviews in Daufresne et al. 2009; Gardner et al. 2011;

83 Sheridan and Bickford 2011). However, a decline in body size caused by

84 climate warming is far from ubiquitous (Meiri et al. 2009; Teplitsky and Millien

85 2014; Gardner et al. 2014a). While some studies found decreases in body size

86 when temperatures increased (e.g. Yom-Tov et al. 2008; Gardner et al. 2009;

87 Van Buskirk et al. 2010), others found no change (e.g. Meiri et al. 2009;

88 Salewski et al. 2010, 2014a, b), and yet others showed an increase (e.g.

89 Björklund et al. 2014; Gardner et al. 2014b). An explanation for this

90 heterogeneous pattern of change in body size may be that it is context

91 dependent such as depending on different sites or even on the same sites in

92 different years (Yom-Tov et al. 2006; Meiri et al. 2009; Collins et al. 2017).

93 Thus, phenotypic changes may depend on short and long term effects of climate

94 (Kruuk et al. 2015). 
Changing body size changes may emerge through effects of environmental conditions on body growth, in particular the effects of protein content of the diet for growth of juveniles (e.g. Searcy et al. 2004; Bonaparte et al. 2016), although again alternative explanations are common. The size of endothermic organisms such as birds is affected by growth conditions and duration of the growth period (Yom-Tov and Geffen 2011). Climatic conditions can directly affect growth rates. Because temperature affects thermoregulation of juveniles, these changes may impact metabolic rates and variation in energy allocation to body growth (Gillooly et al. 2001). While climate conditions may affect growth rates, they may also affect eventual body size due to sizedependent mortality (such as that caused by heat waves or dehydration (McKechnie and Wolf 2010)).

Previous studies of climate change effects on morphology have focused on reductions in size, while there is an extensive history of studies dealing with effects of temperature on developmental instability (DI), as shown by temporal changes in asymmetry (a measure of DI) with environmental fluctuations (e.g. Beardmore 1960; Siegel and Doyle 1975; Mooney et al. 1985; Gest et al. 1986). Absolute fluctuating asymmetry (AFA) reflected as the difference in size between the sides of a character has been shown more generally to increase with adverse environmental conditions including increased and stressful temperatures (reviews in Møller and Swaddle 1997; Beasley et al. 2013). Not only can this be important for evaluating the effects of climate change on how it 
117 causes stress during development, but causal effects of climate change on

118 asymmetry can have functional implications as well, where, for example, larger

119 wing asymmetry decreases flight performance (Swaddle, 1997). Thus, on the

120 one hand, if DI reflects stress, health and/or 'individual quality', one would

121 expect associations between AFA and for example temperature to be expressed

122 in all traits. However, there is evidence that the AFA-stress relationship may be

123 trait-specific, and little is known about the factors affecting this heterogeneity

124 (Lens et al., 2002; Van Dongen, 2006; but see Van Dongen et al., 2009; De

125 Coster et al., 2013), especially because very large sample sizes are required to

126 detect such differences in responses between traits in single studies, a problem

127 that is not present in this study.

128 A third component of phenotypic variation is canalization, which reflects

129 the ability of a genotype to produce relatively constant phenotypes under

130 different environmental conditions (Waddington 1942; Scharloo 1991). Not all

131 traits are canalized similarly because traits vary in their functional importance.

132 Hence the degree to which such traits have been selected to result in similar

133 developmental trajectories even when encountering different or adverse

134 environmental conditions may vary. As such, the degree of canalization may

135 affect the effects of adverse conditions on DI and thus AFA. It can thus be

136 predicted that due to the evolutionary history of traits, effects of climate change

137 vary among different body parts. Indeed, Van Dongen et al. (2009) and De

138 Coster et al. (2013) showed that the evolutionary history of a trait can influence 
139 the association between AFA and stress. Similarly, it is likely that the time

140 window during which stress is experienced may make some traits more

141 vulnerable to increased DI than others. Making specific predictions is often

142 difficult as different factors can simultaneously influence particular traits. For

143 example, some traits, like the tarsus in birds, develop largely before fledging,

144 while size and asymmetry of feathers can change after each molt (e.g., Swaddle,

145 1997). Nevertheless, we predict that wings in particular are highly stabilized

146 traits given their functional importance, and that should particularly be the case

147 in birds migrating over very long distances. To what extent higher canalization

148 would, if any, either increase or decrease DI of such traits is currently unknown,

149 and is a specific aim of this study.

150 The objectives of this study were to assess (1) whether size decreased

151 with summer temperature, varied among characters and whether the temperature

152 effect differed among characters, (2) whether absolute fluctuating asymmetry

153 (AFA; a measure of developmental instability) differed among characters and

154 with summer temperature and migration distance, and (3) whether the observed

155 differences in AFA-temperature associations could be explained by trait

156 functionality, canalization and/or timing of development. To this end, we

157 analyzed a total of 8993 specimens belonging to 387 species of birds. The

158 analyses were eventually restricted to 66 species with a minimum of 20

159 specimens per species, and in total 5533 asymmetry values in 1593 birds from

160 Christiansfeld and surroundings, Denmark. 


\section{Materials and methods}

163

164

165

166

167

\section{STUDY SITES AND ORIGIN OF SPECIMENS}

Johannes Erritzøe (JE), who is a taxidermist, receives dead birds delivered by the public from the surroundings of Christiansfeld, Denmark (55³6N, $\left.9^{\circ} 49^{\prime} \mathrm{E}\right)$, Denmark. He has collected such specimens since 1960. The general area, where the specimens were found, is largely agricultural with small plantations and villages. The specimens are found dead, killed by collision with wires, windows or cars, shot or found dead for other reasons. All specimens are sexed and aged using gonads or plumage characteristics as reported in Svensson (2006).

\section{MEASUREMENTS}

JE measured more than 40 characters, including the five characters that were measured twice to allow discrimination between measurement error and fluctuating asymmetry. JE measured twice right and left side of the flattened wing for 2459 individual birds, tail length for 1247, tarsus length for 1816, femur length for 1840 and humerus length for 1963 individual birds to allow for estimation of size and size-scaled and log-transformed absolute fluctuating asymmetry (AFA). All feather measurements were made with a ruler to the nearest $0.5 \mathrm{~mm}$ and skeletal measurements were made with a digital caliper with a precision of $0.01 \mathrm{~mm}$ when bones had been fully cleaned, removed from specimen and measured as described above. Repeat measurements were made 
183 first by measuring the character on the right side, then the left side, then the

184 right side and finally the left side to avoid any bias in measurements. JE took

185 great care to use clearly defined landmarks at the two ends of skeletal characters

186 before making the measurements as described above. All specimens were

187 measured by JE thereby avoiding any variation among observers. The

188 measurements were made blindly with respect to the hypotheses under test,

189 thereby preventing any observer expectations.

190

191 ENVIRONMENTAL CONDITIONS

192 We used mean summer temperature during the months May-August estimated

193 as the temperature anomaly for all years 1949-2017

194 (http://cib.knmi.nl/mediawiki/index.php/European_climate_in_2017). Surface

195 air temperatures are measured at an extensive network of weather stations in

196 Europe. These data are collected and aggregated into European temperatures.

197 The annual mean values in this E-OBS

198 (http://www.ecad.eu/download/ensembles/ensembles.php) dataset are estimated

199 for the land area between $35^{\circ}-75^{\circ} \mathrm{N}$ and $25^{\circ} \mathrm{W}-45^{\circ} \mathrm{E}$. We decided to rely on

200 aggregated weather data over large spatial scales because the specimens that we

201 obtained derived from a large spatial scale during migration and reproduction.

202 Local climate data from the main study site at Taps, Christiansfeld, Denmark

203 provided very similar conclusions. 


\section{MIGRATION DISTANCES}

We estimated migration distance as the difference in latitude between the mean of the northernmost and the southernmost breeding distribution in degree latitude and the mean of the northernmost and the southernmost winter distribution in degree latitude, relying on information in Cramp and Perrins (1977-1994) and del Hoyo et al. (1995-2008). Migration distance ranged from 0 to $71^{\circ}$ latitude with a mean value of $13.9^{\circ}(\mathrm{SE}=2.22)$ for the 66 species that were included in the analyses.

\section{ESTIMATING SIZE AND ABSOLUTE FLUCTUATING ASYMMETRY}

After selecting species with 20 or more measured specimens, size was obtained for each trait and individuals were averaged across the repeated measurements on both sides. In order to be able to analyze the association between size and summer temperature, size was standardized for each species such that the scale of measurement was identical for all species.

To obtain absolute fluctuating asymmetry (AFA) estimates for each trait and individual, first a mixed model was run to separate FA from measurement error and to correct for directional asymmetry. To achieve this, signed asymmetries were calculated for each individual-trait combination on the basis of the first and the second repeated measurements. Both were divided by trait size such that all signed FA's were expressed as a proportion of trait size. Next, a mixed model was run with signed FA as response variable and individual as 
227 random effect. The intercept of this model will test for directional asymmetry,

228 whereas the between-individual variation reflects real FA and the residual

229 variation the degree of measurement error. The results are provided in Table 1,

230 showing that measurement error was smaller than $10 \%$, and that right biased

231 directional asymmetry was present for tails, wings and femur, while for

232 humerus directional asymmetry was left biased. This DA could reflect a real

233 biological phenomenon, or it could originate from the handedness of the

234 measurer (Helm and Albrecht, 2000). Differences in DA among traits have also

235 been observed in humans and may have functional importance (related to

236 behavioral lateralization; Auerbach and Ruff, 2006), but also be of

237 developmental origin (Van Dongen et al., 2014). Absolute values of the random

238 individual effects were used as estimates of AFA, thus after correcting for

239 measurement error and directional asymmetry.

241 STATISTICAL ANALYSES

242 The analysis of AFA in relation to summer temperature and migration distance

243 was performed for all traits in one overall mixed model. In this model, summer

244 temperature, migration distance, trait, all two-way interactions and the three-

245 way interaction were treated as fixed effects. Individual, species, genus and

246 family were added as random effects. In addition, the species-summer

247 temperature interaction was also added as a random effect, to obtain the

248 appropriate tests and degrees of freedom for the fixed effects analysis, thus 
249 assuming that species are the independent unit of observation. A species-

250 migration distance interaction could not be added as migration distance is a

251 species-specific characteristic. Degrees of freedom were approximated using the

252 Kenward-Roger method (Kenward and Roger 1997). In case of significant

253 interactions between trait and either summer temperature or migration distance,

254 indicating that associations between AFA and summer temperature or migration

255 distance differed among traits, the above mixed model was run for each trait

256 separately (and without the random individual effect, because there were no

257 longer repeated measurements). A similar analysis was performed for trait size.

258 However, since the size of each trait was standardized at the level of species for

259 each trait, all variation among species, genera and families was a priori removed

260 from the variation in size. In addition, as migration distance is a species-specific

261 trait, it was also removed from the model. Thus, the mixed model contained

262 trait, summer temperature and the trait-summer temperature interaction as fixed

263 effects, and the summer temperature-species interaction as random effect.

264 Degrees of freedom were approximated using the Kenward-Rogers method. The

265 advantages of using such complex mixed models is that it allows to explicitly

266 model and test for interactions and thus statistically compare patterns across 267 traits.

All analyses were performed in the package $\mathrm{R}$ (version 3.3; R Core Team 2017) using the package lmerTest and the function lmer. 
271

272

273

27

275

276

277

278

279

280

281

282

283

284

285

286

287

288

289

290

291

\section{Results}

\section{CLIMATE CHANGE}

Climate changed significantly during 1948-2016. Annual temperature anomaly has increased since 1948 by $+0.5921(\mathrm{SE}=0.0546){ }^{\circ} \mathrm{C} /$ year, or by $+0.0404{ }^{\circ} \mathrm{C}$ $(\mathrm{SE}=0.0076)$ during $1948-2016\left(F_{1,67}=28.55, R^{2}=0.29, P<0.0001\right)$. Local temperature at the study site in Denmark was strongly positively correlated with the annual temperature anomaly during 1971-2017 $\left(F_{1,44}=22.28, R^{2}=0.32, P<\right.$ 0.0001$, slope $(\mathrm{SE})=1.0397(0.2203))$.

\section{SIZE, FA, CANALIZATION AND CLIMATE WARMING}

There was no significant interaction between trait and summer temperature for the mixed model analyzing trait size $\left(F_{4,5990}=0.46, P=0.76\right)$, suggesting that the change in size with summer temperature is comparable for all traits. Indeed, the overall association between size and summer temperature was statistically significant $\left(F_{1,135}=9.47, P=0.003\right)$, even though it was not statistically significant for each individual trait (Fig. 1).

AFA did not differ substantially among individuals ( $0.3 \%)$, species $(0.7 \%)$, genera $(0.6 \%)$ or families $(1.9 \%)$, as these four hierarchical levels together explained only $3.5 \%$ of the variation in AFA. Average asymmetry did differ among traits, where the lowest values were observed for wing and femur (Table 1), suggesting that these traits were most strongly canalized. 
For the mixed model of AFA, there was no significant three-way

293 interaction between trait, summer temperature and migration distance $\left(F_{4,94}=\right.$

$2940.34, P=0.85$ ), nor was there a significant interaction between summer

295 temperature and migration distance $\left(F_{1,556}=0.20, P=0.66\right)$. A statistically

296 significant interaction was found between trait and summer temperature $\left(F_{4,77}=\right.$

$2973.42, P=0.01)$ and between trait and migration distance $\left(F_{4,3004}=5.21, P=\right.$

298 0.0004). This indicates that the association between AFA and both summer

299 temperature and migration distance differed among traits. Analyses for each

300 trait separately showed that there was a significant increase in AFA with

301 summer temperature for wings only (Fig. 2). In addition, AFA showed a

302 significant negative association with migration distance for wings only (Fig. 3).

\section{Discussion}

305 There is an extensive literature on the effects of climate warming on size, albeit 306 clearly heterogeneous (reviews in Gardner et al. 2011; Sheridan and Bickford 307 2011). Here we have taken these analyses a step further by comparing patterns 308 among characters which differ in functional importance, level of canalization

309 and timing of development. In contrast, most previous studies have only 310 analyzed one or a couple of characters and analyzed average AFA. However, it 311 is not clear if DI can be considered to be an individual or 'genome-wide' trait 312 and associations could vary among traits. This raises questions about the 
314 as stated in recent reviews (Gardner et al. 2011; Sheridan and Bickford 2011),

315 especially if there are good reasons to predict different responses of different

316 characters.

317 Within- and among-individual variation in absolute fluctuating asymmetry

318 (AFA) and size of two feather and three skeletal characters in birds during the

319 last 57 years revealed a significant increase in wing asymmetry and a decrease

320 in overall size with summer temperature. The degree of AFA differed among

321 characters, with the lowest degree of FA in wings and femur, suggesting that

322 these traits were more strongly canalized. Absolute fluctuating asymmetry in

323 both wings and femur decreased with migration distance. These patterns of

324 phenotypic variation imply that DI of the most important functional trait

325 (wings) is more impacted by temperature than tails, tarsus, femur and humerus,

326 and DI of the two most canalized traits is negatively related to migration

327 distance.

328 Indeed, we hypothesized that migratory species should be subject to more

329 intense selection against AFA in wings that are directly involved in flight and

330 hence in long-distance migration. Indeed, the morphology of the flight

331 apparatus is known to be related to migration with implications for wingspan,

332 wing area, aspect ratio and wing loading (e.g. Norberg 1990; Rayner 1990;

333 Vágási et al. 2016). In contrast, there was no comparable effect for tail, tarsus or

334 humerus length. Migratory birds have been subject to a particularly intense

335 history of selection, while that is not the case for resident species. Therefore, we 
336 should expect that such traits subject to intense selection would have a high

337 degree of canalization (Waddington 1942; Scharloo 1991). Indeed, there is

338 currently strong selection on the locomotor apparatus in migrants (e. g. Møller

339 et al. 2011a, b; Teplitsky et al. 2011). Canalization reflects the ability of a

340 population to produce a single phenotype independent of variability in the

341 environment (Waddington 1942; Scharloo 1991). However, not all traits are

342 canalized similarly because traits vary in their functional importance and hence

343 the degree to which such traits have been selected to result in similar

344 developmental trajectories even under different adverse environmental

345 conditions. Because the three-way interaction between temperature, migration

346 distance and character was not statistically significant, the relationship between

347 AFA and temperature was comparable for migratory and resident species.

348 Indeed, for wings, the associations between AFA and both temperature and

349 migration patterns are in agreement with our hypothesis that high functional

350 importance would increase canalization and result in a trait DI that is more

351 vulnerable for environmental stress, even though it is obviously important to

352 note that we cannot prove this from our correlational data.

353 For the femur, however, it remains difficult to explain why AFA would

354 relate negatively to migration distance. A speculative explanation might be that

355 the femur is morphologically associated with the muscles of the upper limb and

356 thus have a relative high amount of mass. Subtle asymmetries might create mass

357 imbalances between the two sides during flight and these need to be 
compensated for constantly and hence be energetically constant. However, to our knowledge, no research has been performed on the relationship between trait asymmetry and flight in birds, except for wings (Swaddle, 1997). Even if one would be able to explain the higher canalization and the negative association between femur AFA and migration distance from a functional point of view, one would expect a positive correlation between femur AFA and temperature as well. Apparently, trait functionality and degree of canalization alone are not sufficient to explain our results.

In conclusion, climate warming has been predicted to affect body size and AFA. Here we have documented such effects for a large number of species and five different characters. While some would argue that patterns in AFA should become expressed in all traits, we show the contrary and suggest that evolutionary history, functional importance and degree of canalization of a trait may predict effects of environmental changes on DI. These novel findings are only to some extent consistent with predictions. Finally, we document that the effect of temperature, that is extensively documented in the literature, is similar in migratory and resident bird species, yet may mainly affects locomotor traits that can have functional consequences, especially in migratory birds. The comparison of AFA-stress associations among traits may offer an interesting strategy to explore the interplay of environmental changes and the evolutionary history of traits for developmental instability and canalization. Ideally, an 
380 experimental approach should be adopted, but may be difficult to achieve when

381 making comparisons among species with different properties, like being

382 migratory or not. Since migrants and residents can be crossed readily, we

383 hypothesize that these questions can be resolved using a quantitative genetic

384 approach.

385 


\section{LITERATURE CITED}

Auerbach, B. M., \& Ruff, C. B. (2006). Limb bone bilateral asymmetry: Variability and commonality among modern humans. Journal of Human Evolution, 50, 203-218.

Beardmore, J. A. 1960. Developmental stability in constant and fluctuating temperatures. Heredity 14:411-422.

Beasley, D. A. E., A. Bonisoli-Alquati, and T. A. Mousseau. 2013. The use of fluctuating asymmetry as a measure of environmentally induced developmental instability: A meta-analysis. Ecol. Indicat. 30: 218-226.

Bergmann, C. 1847. Über die Verhältnisse des Warmeökonomie der Thiere zu ihrer Grösse. Göttinger Studien 3: 595-708.

Björklund, M., A. Borras, J. Cabrera, and J. C. Senar. 2015. Increase in body size is correlated to warmer winters in a passerine bird as inferred from time series data. Ecol. Evol. 5 (1): 59-72.

Bonaparte, K. M., C. Riffle-Yokoi, and N. T. Burley. 2011. Getting a Head Start: Diet, Sub-Adult Growth, and Associative Learning in a Seed-Eating Passerine. PLoS One 6(9): e23775.

Collins, M. D., G. E. Relyaea, E. C. Brustein, and S. M. Badami. 2017. Heterogeneous changes in avian body size across and within species. J. Ornithol. 158: 39-52.

Cramp, S., and C. M. Perrins. (eds) 1977-1994. The birds of the Western Palearctic. Vols. 1-9. Oxford University Press, Oxford, UK. 
408 Daufresne, M., K. Lengfellner, and U. Sommer. 2009. Smallest algae thrive as the Arctic Ocean freshens. Proc. Natl. Acad. Sci. USA 106: 1278812793.

Dayan, T., D. Simberloff, E. Tchernov, and Y. Yom-Tov. 1991. Calibrating the paleothermometer: Climate, communities, and the evolution of size. Paleobiol. 17: 189-199.

De Coster, G., S. van Dongen, P. Malaki, M. Muchane, A. Alcántara-Exposito, and H. Matheve. 2013. Fluctuating asymmetry and environmental stress: Understanding the role of trait history. PLoS One 8 (3): e57966.

del Hoyo, J., A. Elliott, and J. Sagartal. (eds) 1992-2008. Handbook of the birds of the World. Lynx, Barcelona, Spain.

Gardner, J. L., R. Heinsohn, and L. Joseph. 2009. Shifting latitudinal clines in avian body size correlate with global warming in Australian passerines. Proc. Biol. Sci. 276: 3845-3852.

Gardner, J. L., A. Peters, M. A. Kearney, J. Joseph, and L. Heinsohn. 2011. Declining body size: A third universal response to warming. Trends Ecol. Evol. 26: 285-291.

Gardner, J. L., T. Amano, P. R. Y. Blackwell, K. Ikin, W. J. Sutherland, and A. Peters. 2014a. Temporal patterns of avian body size reflect linear size responses to broadscale environmental change over the last 50 years. J. Avian Biol. 45; 1-7. 
429 Gardner, J. L., T. Amano, B. Mackey, W. J. Sutherland, M. Clayton, and A. Peters. 2014b. Dynamic size responses to climate change: Prevailing effects of rising temperature drive long-term body size increases in a semiarid passerine. Global Change Biol. 20: 206-2075.

Gest, T. R., M. I. Siegel, and J. Anistranski. 1986. The long bones of neonatal rats stressed by cold, heat, and noise exhibit increased fluctuating asymmetry. Growth 50: 385-389.

Gillooly, J. F., J. H. Brown, G. B. West, V. W. Savage, and E. L. Charnov. 2001. Effects of size and temperature on metabolic rate. Science 293: $2248-2251$

Helm, B. and Albrecht, H. 2000. Human handedness causes directional asymmetry in avian wing length measurements. Anim. Behav. 60: 899902.

James, F. C. 1970. Geographic size variation in birds and its relationship to climate. Ecology 51: 365-390.

Kenward, M., and J. Roger. 1997. Small Sample Inference for Fixed Effects from Restricted Maximum Likelihood. Biometrics 53: 983-997.

Kruuk, L. E. B., H. L. Osmong, and A. Cockburn. 2015. Contrasting effects of climate on juvenile body size in a Southern Hemisphere passerine bird. Global Change Biol. 21: 2929-2941. 
449 Lens, L., Van Dongen, S., Kark, S., and E. MATTHYSEN 2002. Fluctuating asymmetry as an indicator of fitness: can we bridge the gap between studies? Biological Reviews 77: 27-38.

452

453

454

455

456

457

458

459

460

461

462

463

464

465

466

467

468

469

McKechnie, A. E., and B. O. Wolf. 2010. Climate change increases the likelihood of catastrophic avian mortality events during extreme heat waves. Biol. Lett. 6: 253-256.

Meiri, S., D. Guy, T. Dayan, and D. Simberloff. 2009. Global change and carnivore body size: Data are stasis. Global Ecol. Biogeogr. 18: 240-247.

Møller, A. P., and J. P. Swaddle. 1997. Asymmetry, developmental stability, and evolution. Oxford University Press, Oxford, UK.

Møller, A. P., C. Biard, F. Karadas, D. Rubolini, N. Saino, and P. F. Surai. 2011a. Maternal effects and changing phenology of bird migration. Climate Res. 49: 201-210.

Møller, A. P., R. Nuttall, S. E. Piper, T. Szép, and E. J. Vickers. 2011 b. Migration, moult and climate change in barn swallows Hirundo rustica in South Africa. Climate Res. 47: 201-205.

Mooney, M. P., M. I. Siegel, and T. R. Gest. 1985. Prenatal stress and increased fluctuating asymmetry in the parietal bones of neonatal rats. Am. J. Phys. Anthropol. 68: 131-134.

Norberg, U. M. 1990. Vertebrate flight: Mechanisms, physiology, morphology, ecology and evolution. Springer, Berlin, Germany. 
470 Olson, V. A., R. G. Davies, C. D. L. Orme, G. H. Thomas, S. Meiri, T. M.

Blackburn, K. J. Gaston, I. P. F. Owens, and P. M. Bennett. 2009. Global biogeography and ecology of body size in birds. Ecol. Lett. 12: 249-259.

R Development Core Team. 2017. R: A language and environment for 474 statistical computing. R Foundation for Statistical Computing. Vienna, Austria.

Rayner, J. M. V. 1990. The mechanics of flight and bird migration performance. In E. Gwinner (Ed.) Bird migration. Physiology and ecophysiology, Pp. 283-299. Springer: Heidelberg, Germany.

Salewski, V., W. Hochachka, and W. Fiedler. 2010. Global warming and Bergmann's rule: Do central European passerines adjust their body size to rising temperatures? Oecologia 162: 247-260.

Salewski, V., W. M. Hochachka, and H. Flinks. 2014a. Changes in stonechat Saxicola torquata morphology: A response to climate change? J. Ornithol. 155: 601-609.

485 Salewski, V., K.-H. Siebenrock, F. Woog, and W. Fiedler. 2014b. adaptation to climatic change. PLoS 9 (7): e101927.

Scharloo, W. 1991. Canalization: Genetic and developmental aspects. Ann. 
490 Searcy, W. A., S. Peters, and S. Nowicki. 2004. Effects of early nutrition on growth rate and adult size in song sparrows Melospiza melodia. J. Avian Biol. 35: 269-279.

Sheridan, J., and D. Bickford. 2011.Shrinking body size as an ecological response to climate change Nature Climate Change 1: 401-406.

Siegel, M. I., and W. J. Doyle. 1975. The effects of cold stress on fluctuating asymmetry in the dentition of the mouse. J. Exp. Zool. Part A 193: 385389.

Svensson, L. 2006. Identification guide to European passerines. British Trust for Ornithology, Thetford, UK.

500 Swaddle, J. P., and M. S. Witter. 1997. The effects of molt on the flight performance, body mass, and behavior of European starlings (Sturnus vulgaris): An experimental approach. Can. J. Zool. 75: 1135-1146.

Teplitsky, C., and V. Millien, V. 2014. Climate warming and Bergmann's rule 504 through time: Is there any evidence? Evol. Appl. 7: 156-168.

505 Teplitsky, C., N. G. Mouawad, J. Balbontín, F. de Lope, and A. P. Møller. 2011. 506 Quantitative genetics of migration syndromes: a study of two barn swallow populations. J. Evol. Biol. 24: 2025-2039.

508 Vágási, C., P. L. Pap, O. Vincze, G. Osváth, J. Erritzøe, and A. P. Møller. 2016. Morphological adaptations to migration in birds. Evol. Biol. 43: 48-59. 
510 Van Buskirk, J., R. S. Mulvihill, and R. C. Leberman. 2010. Declining body sizes in North American Birds associated with climate change. Oikos 119: 1047-1055.

513 Van Dongen, S. 2006. Fluctuating asymmetry and developmental instability in evolutionary biology: Past, present and future. J. Evol. Biol. 19: 17271743

Van Dongen, S., L. Lens, E. Pape, F.A.M. Volckaert, and J. A. M. Raeymaekers. 2009. Evolutionary history shapes the association between developmental instability and population-level genetic variation in threespined sticklebacks. J. Evol. Biol. 22: 1695-1707.

Van Dongen, S., Galis, F., Ten Broek, C., Heikinheimo, K., Wijnaendts, L.C.D., Delen, S., and J. Bots 2014. When right differs from left: Human limb directional asymmetry emerges during very early development, Laterality: Asymmetries of Body, Brain and Cognition, 19: 591-601

Van Gils, J. A., S. Lisovski, S. Lok, W. Meissner, A. Ozarowska, J. de Fouw, E. Rakhimberdiev, M. Y. Soloviev, M. Piersma, and M. Klaassen. 2016. Body shrinkage due to Arctic warming reduces red knot fitness in tropical wintering range. Science 352: 819-821.

528 Waddington, C. H. 1942. Canalization of development and the inheritance of acquired characters. Nature 150: 563-565. 
530 Yom-Tov, Y., and E. Geffen. 2011. Recent spatial and temporal changes in 531 body size of terrestrial vertebrates: Possible causes and pitfalls. Biol. Rev. $532 \quad 86: 531-541$.

533 Yom-Tov, Y., S. Yom-Tov, J. Wright, C. J. R. Thorne, and R. Du Feu. 2006.

$534 \quad$ Recent changes in body weight and wing length among some British $535 \quad$ passerine birds. Oikos 112: 91-101.

536 Yom-Tov, Y., S. Yom-Tov, and G. Jarrell. 2008. Recent increase in body size 537 of the American marten Martes americana in Alaska. Biol. J. Linn. Soc. $538 \quad 93: 701-707$. 
540

541

542 Figure 1. Size of five morphological characters in relation to annual

543 temperature in 66 species of birds. The associations were significant for tail ( $\beta$

$\left.544=-0.141 \pm 0.046 ; \mathrm{t}_{932}=-3.04, \mathrm{p}=0.002\right)$ and tarsus $\left(\beta=-0.081 \pm 0.041 ; \mathrm{t}_{1126}=-\right.$

$5451.98, \mathrm{p}=0.05)$, but not for wing $\left(\beta=-0.053 \pm 0.033 ; \mathrm{t}_{1700}=-1.64, \mathrm{p}=0.10\right)$,

546 femur $\left(\beta=-0.012 \pm 0.041 ; \mathrm{t}_{1074}=-0.30, \mathrm{p}=0.76\right)$ and humerus $(\beta=-0.033 \pm$

$\left.5470.039 ; \mathrm{t}_{1184}=-081, \mathrm{p}=0.40\right)$. Since there was no significant interaction between

548 trait and summer temperature, our results suggest that the size of all traits

549 showed a similar association with summer temperature (see text for further

550 details). The lines are the linear regression lines.

552 Figure 2. Absolute fluctuating asymmetry (AFA, expressed as a percentage of

553 trait size) in relation to annual temperature anomaly for five different

554 morphological characters in 66 species of birds. The associations were

555 statistically significant for wing $\left(\beta=0.079 \pm 0.031 ; t_{42}=2.55, P=0.01\right)$, but not

556 for tail $\left(\beta=0.058 \pm 0.034 ; t_{25}=1.63, P=0.12\right)$, tarsus $\left(\beta=0.013 \pm 0.032 ; t_{26}=\right.$

$5570.38, P=0.71)$, femur $\left(\beta=-0.019 \pm 0.032 ; t_{26}=-0.58, P=0.57\right)$ and humerus $(\beta$ $\left.558=-0.040 \pm 0.030 ; t_{29}=-1.27, P=0.15\right)$. The lines are the linear regression lines. 
562 Figure 3. Absolute fluctuating asymmetry (AFA, expressed as a percentage of

563 trait size) in relation to migration distance for five different morphological

564 characters in 66 species of birds. The associations were statistically significant

565 for wing $\left(\beta=-0.098 \pm 0.034 ; t_{56}=-2.89, P=0.004\right)$ and femur $(\beta=-0.086 \pm$

$\left.5660.038 ; t_{56}=-2.29, P=0.02\right)$, but not for tail $\left(\beta=0.020 \pm 0.041 ; t_{55}=0.49, P=\right.$

$5670.62)$, tarsus $\left(\beta=0.042 \pm 0.038 ; t_{56}=1.12, P=0.26\right)$ and humerus $(\beta=0.029 \pm$

$\left.5680.038 ; t_{56}=0.77, P=0.44\right)$. The lines are the linear regression lines. 
570

571 
$572 \quad$ Fig. 1

573
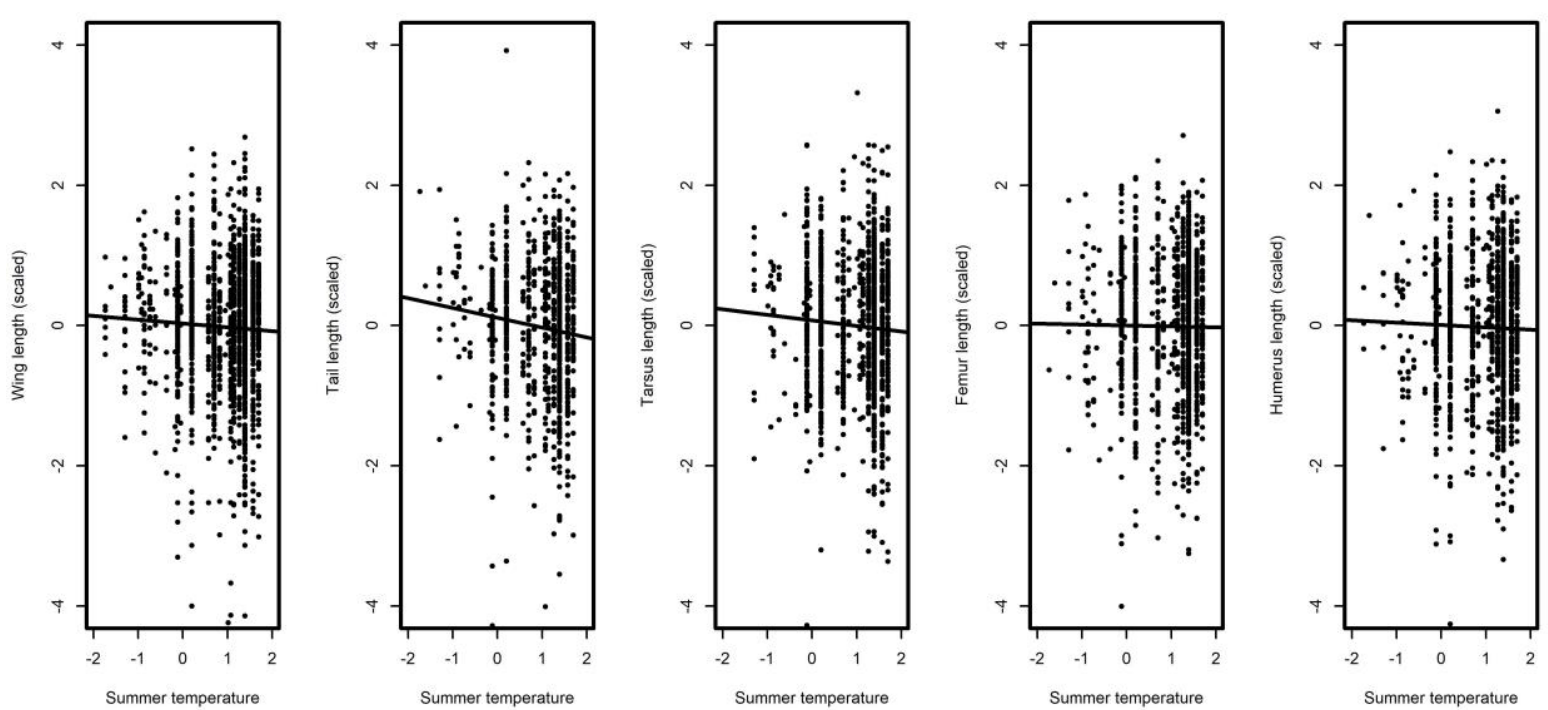

575

$576 \quad$ Fig. 2
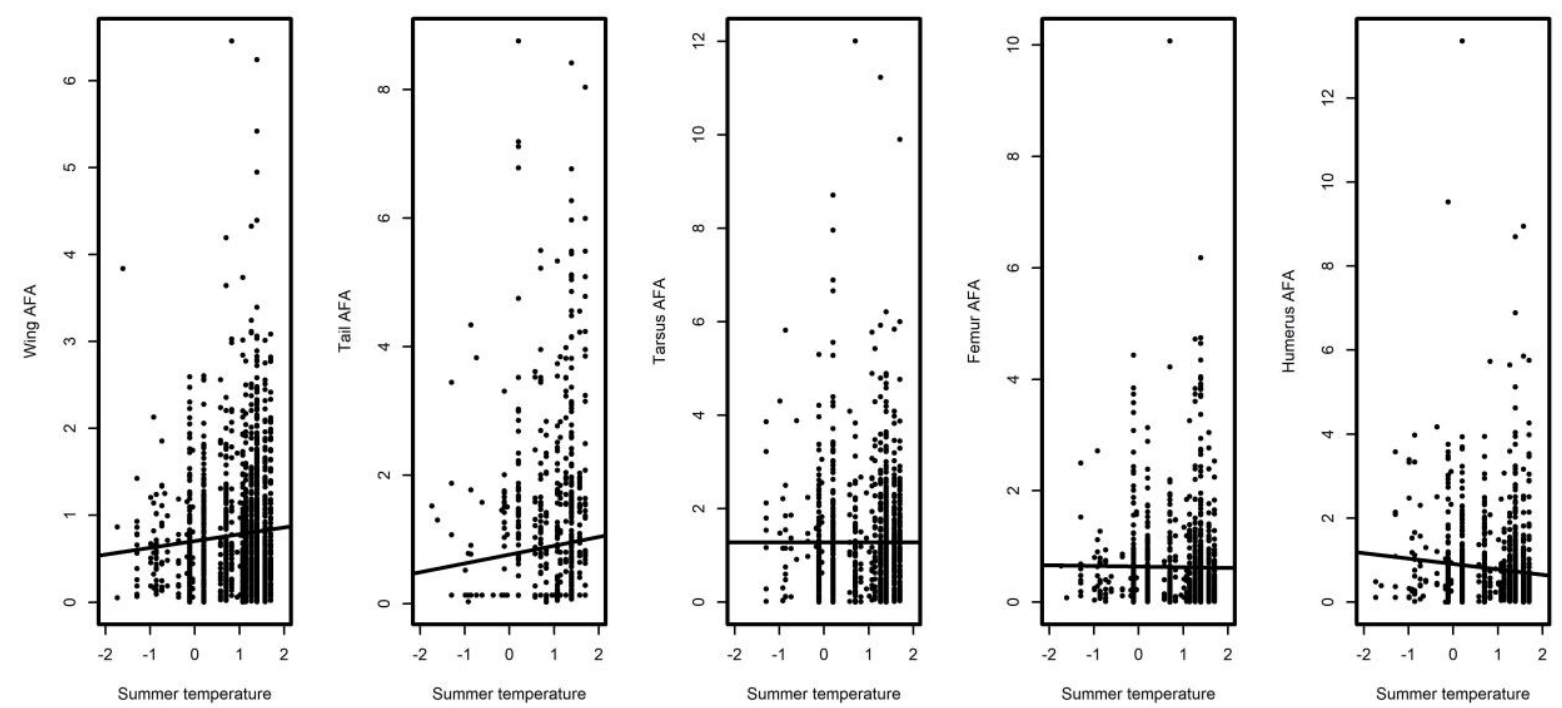
578

579

580 
$581 \quad$ Fig. 3
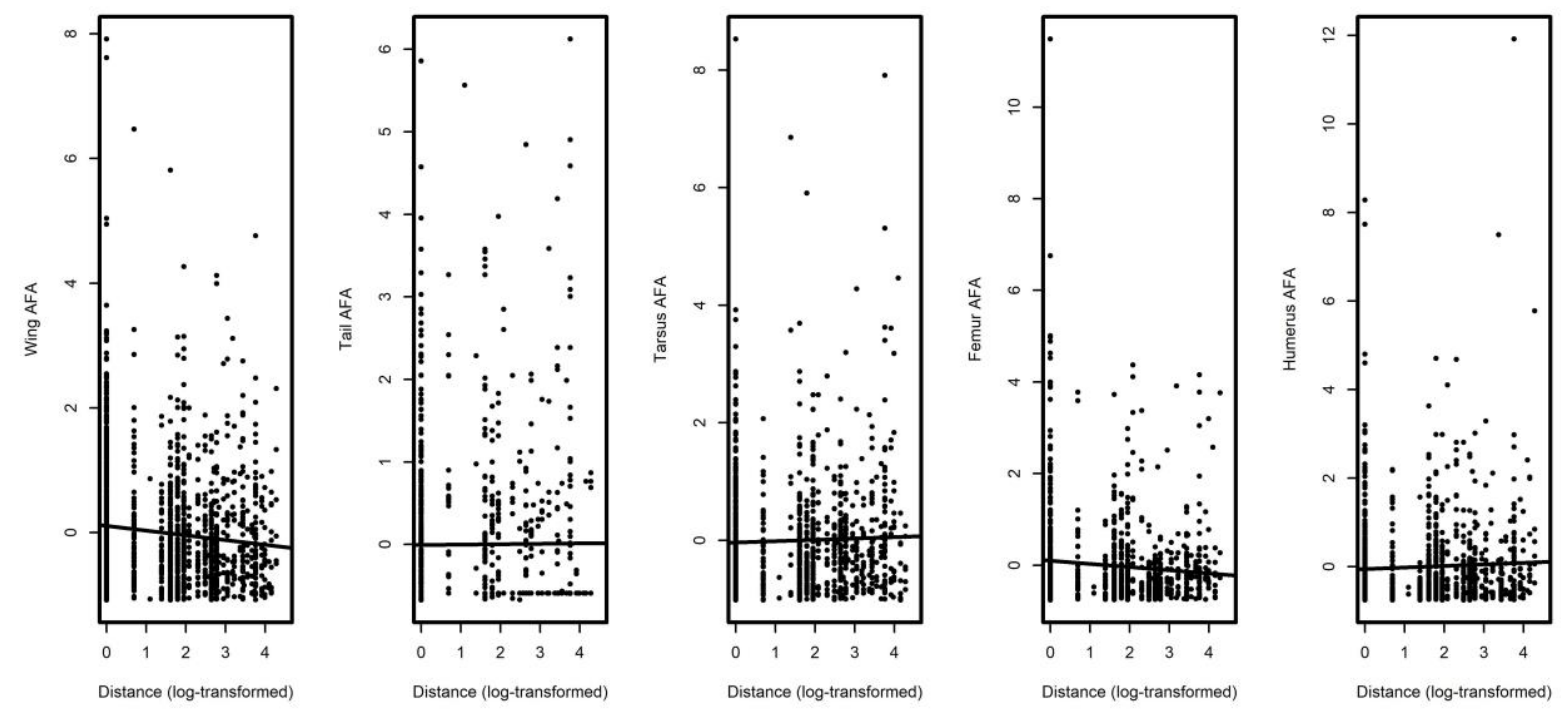
584 Table 1. Analysis of measurement error and directional asymmetry in the five 585 characters of birds. Variation in size scaled signed asymmetry (expressed as a 586 percentage relative to size) was partitioned into directional asymmetry (DA, 587 positive values reflecting that the right side on average was larger than the left), 588 variation in fluctuating asymmetry (FA) and variation in measurement error 589 (ME).

590

59

Trait

FA $\quad$ ME $\%$ FA

DA [mean (SD), t-test]

P

592 Wing

$\begin{array}{lll}1.21 & 0.12 \quad 91 \%\end{array}$

$0.38(0.02), \mathrm{t}_{2118}=15.3<0.0001$

593 Tail

$2.28 \quad 0.08 \quad 97 \%$

$0.13(0.05), \mathrm{t}_{1111}=2.91 \quad 0.004$

594 Tarsus

$3.35 \quad 0.35 \quad 91 \%$

$-0.04(0.05), \mathrm{t}_{1517}=0.80 \quad 0.42$

595 Femur

$1.32 \quad 0.03 \quad 97 \%$

$0.20(0.03), \mathrm{t}_{1425}=6.40<0.0001$

596 Humerus

$1.82 \quad 0.12 \quad 94 \%$

$-0.12(0.04), \mathrm{t}_{1552}=3.25 \quad 0.001$ 